Article

\title{
Designing of Drive Systems in the Aspect of the Desired Spectrum of Operation
}

\author{
Tomasz Dzitkowski $^{1} \oplus$, Andrzej Dymarek ${ }^{1, *}{ }^{\mathbb{D}}$, Jerzy Margielewicz ${ }^{2}$, Damian Gąska ${ }^{2}$, Lukasz Orzech ${ }^{3} \mathbb{C}$ \\ and Krzysztof Lesiak 3 (D) \\ 1 Department of Engineering Processes Automation and Integrated Manufacturing Systems, Silesian \\ University of Technology, Konarskiego 18A, 44-100 Gliwice, Poland; tomasz.dzitkowski@polsl.pl \\ 2 Department of Air Transport, Silesian University of Technology, Krasińskiego 8, 40-003 Katowice, Poland; \\ jerzy.margielewicz@polsl.pl (J.M.); damian.gaska@polsl.pl (D.G.) \\ 3 Laboratory of Applied Tests, KOMAG Institute of Mining Technology, Pszczynska 37, 44-101 Gliwice, Poland; \\ lorzech@komag.eu (L.O.); klesiak@komag.eu (K.L.) \\ * Correspondence: andrzej.dymarek@polsl.pl
}

Citation: Dzitkowski, T.; Dymarek, A.; Margielewicz, J.; Gaska, D.; Orzech, L.; Lesiak, K. Designing of Drive Systems in the Aspect of the Desired Spectrum of Operation. Energies 2021, 14, 2562. https:// doi.org/10.3390/en14092562

Academic Editor: Federico Barrero

Received: 31 March 2021

Accepted: 27 April 2021

Published: 29 April 2021

Publisher's Note: MDPI stays neutral with regard to jurisdictional claims in published maps and institutional affiliations.

Copyright: (c) 2021 by the authors. Licensee MDPI, Basel, Switzerland. This article is an open access article distributed under the terms and conditions of the Creative Commons Attribution (CC BY) license (https:// creativecommons.org/licenses/by/ $4.0 /)$.

\begin{abstract}
A method for selecting dynamic parameters and structures of drive systems using the synthesis algorithm is presented. The dynamic parameters of the system with six degrees of freedom, consisting of a power component (motor) and a two-speed gearbox, were determined, based on a formalized methodology. The required gearbox is to work in specific resonance zones, i.e., meet the required dynamic properties such as the required resonance frequencies. In the result of the tests, a series of parameters of the drive system, defining the required dynamic properties such as the resonance and anti-resonance frequencies were recorded. Mass moments of inertia of the wheels and elastic components, contained in the required structure of the driving system, were determined for the selected parameters obtained during the synthesis.
\end{abstract}

Keywords: drive system; torsional vibration; synthesis; resonance zones; dynamic properties

\section{Introduction}

Increasing demands are faced by machines concerning not only their manufacturing properties, durability, efficiency, and safety, but also quiet and smooth operation. Dynamic properties of the structure are one of the basic criteria used in designing state-of-theart mechanical structures. They have a direct impact on vibrations, noise emissions, fatigue strength, controllability, and stability. Vibration tests are important both at the designing stage and at the stage of adapting the existing machines to the requirements of production processes. Due to the complexity of the machine structure, these tests are mostly limited to those machine components, whose vibrations have a direct impact on noise emissions, fatigue strength, controllability, and stability. The drive system is a component of the majority of machines, whose dynamic properties should be tested in particular [1-5]. An advance in technology forced the designers of drive systems to ensure high operational durability and reliability of these devices. Therefore, even at the designing stage, it is necessary to deal with these problems, which may become the cause of disturbances in the operation of machines, causing drastic deterioration of operational conditions. Optimization of the system parameters plays an important role in designing the drive systems, especially gearboxes. The optimization may concern geometric parameters such as module, the number of teeth, or clearances [5-8], but also dynamic parameters-mass moments of inertia of wheels and elastic components of the designed gearbox, meeting the predetermined properties, e.g., in the form of required frequency spectrum [9-11]. Therefore, dynamic properties of the structure, described in the form of frequency transition functions are one of the basic criteria used at the designing stage of the state-of-the-art mechanical structures [12-18]. Their knowledge enables the avoidance of 
operating the system in resonance zones, which affects the durability and proper operation of the device. The system parameters can be selected, regarding the dynamic properties, by using the optimization algorithms [5-7], modeling [19-22], or synthesis [9-18], due to an introduction of simulation tests with the use of computers. Simulation tests, belonging to the scope of theoretical tests, allow us to analyze the impact of the selected parameters on mechanical characteristics. These tests give seemingly accurate results but are burdened with a fundamental deficiency, which is an idealization of models in relation to the real object under testing. However, despite these shortcomings, simulation tests develop rapidly. This is due to reducing the cost of such tests in relation to experimental tests. At the same time, these tests allow to conduct an analysis of emergency states and to shorten the time of design processes. Therefore, having an appropriate model of the machine, it is possible to take into account various factors that have a significant impact on its technical parameters, already at the designing stage $[23,24]$. At the same time, the quality of the model used by the designer, understood as the precision of recreating important phenomena occurring in the real system, has a fundamental impact on the accuracy of decisions made at the designing stage, related to a selection of the optimal solution or the appropriate design form of the machine. This article attempts to solve the problem of designing the drive system in the aspect of the desired frequency spectrum. The formalized method, based on the methods of synthesis of vibrating mechanical systems [9-18], reduces the task to a determination of dynamic parameters included in the required drive system. Using this formalized method, the parameters (mass moments of inertia of the wheels and elastic components) of the two-speed gearbox (of a specific ratio) were determined, meeting the desired dynamic properties in the form of a specific frequency spectrum. This approach enables the determination of optimal parameters of the system due to the required dynamic properties already at the design stage, which distinguishes the formalized method from the previous methods of designing drive systems.

\section{Synthesis of Multi-Stage Drive Systems}

The first stage of drive systems synthesis consists of the construction of the dynamic characteristics which are used in the synthesis of discrete mechanical systems, vibrating torsionally $[10,11]$. In this work a determination of the dynamic characteristics form consists in an acceptance of the sequence of resonance and anti-resonance frequencies (of poles and zeros of the searched dynamic characteristics) in the form:

$$
\omega_{b 1}<\omega_{z 1}<\omega_{b 2}<\omega_{z 2}<\cdots<\omega_{b(i-1)}<\omega_{b i}
$$

where: $\omega_{b 1}, \omega_{b 2}, \cdots, \omega_{b i}$-resonance frequencies; $\omega_{z 1}, \omega_{z 2}, \cdots, \omega_{z i}$-anti-resonance frequencies; $i=1,2,3, \cdots, n$.

Based on the dynamic properties, accepted in such a way characteristics functions in the form of dynamic flexibility $Y(s)$ or dynamic stiffness $Z(s)$ are determined and defined as:

$$
Y(s)=\frac{1}{Z(s)}=Y_{11}(s)=\frac{\varphi_{1}(s)}{F_{1}(s)},
$$

where: $s$-Laplace operator $s=\mathrm{i} \omega ; \varphi_{1}(s)$-Laplace transform of the angular displacement of the first synthesized inertial element determined at the zero initial conditions.

Within the framework of these investigations the cases of semi-determined systems (in which the zero resonance frequency, $\omega_{b 1}=0$ occurs), in which the number of the elements of the obtained system is odd, are analyzed. Then the condition 1. $\omega_{b i}>l . \omega_{z j}$ occurs between the number of resonance frequencies $1 . \omega_{b i}$ and anti-resonance ones $1 . \omega_{z j}$ $(j=1,2,3, \cdots, n-1)$, however, the characteristic function accepts the form of the slowness of synthesized half-determined systems:

$$
Y(s)=\frac{1}{Z(s)}=\frac{\left(s^{2}+\omega_{z 1}^{2}\right)\left(s^{2}+\omega_{z 2}^{2}\right) \cdots\left(s^{2}+\omega_{z(n-1)}^{2}\right)}{s^{2}\left(s^{2}+\omega_{b 2}^{2}\right)\left(s^{2}+\omega_{b 3}^{2}\right) \cdots\left(s^{2}+\omega_{b n}^{2}\right)} .
$$


The function of slowness (mechanical impedance) is a dynamic function applied in the synthesis of analyzed drive systems. To reach this objective, in relation to the accepted function, Equation (2), describing dynamic properties of the vibrating discrete system, the following transformation is used:

$$
U(s)=\frac{1}{s} Z(s)=\frac{s\left(s^{2}+\omega_{b 2}^{2}\right)\left(s^{2}+\omega_{b 3}^{2}\right) \cdots\left(s^{2}+\omega_{b n}^{2}\right)}{\left(s^{2}+\omega_{z 1}^{2}\right)\left(s^{2}+\omega_{z 2}^{2}\right) \cdots\left(s^{2}+\omega_{z(n-1)}^{2}\right)}
$$

The defined function of slowness, Equation (3), will be used for structural and parametric syntheses of the drive system, in this work.

In the synthesis of multi-stage driving systems, the systems obtained by distribution of the characteristics into a continued fraction [9] and the mixed method [11,12] are used.

The form of synthesized characteristics, in Equation (3), becomes a chain fraction:

$$
U(s)=I_{1} s+\frac{1}{\frac{s}{c_{1}}+\frac{1}{I_{2} s+\cdots+\frac{s}{\frac{s}{c_{n-1}}+\frac{1}{I_{n} s}}}}
$$

of the mixed form:

$$
U(s)=I_{1} s+\frac{1}{\frac{s}{c_{22}}+\frac{1}{I_{22} s+\cdots+\frac{s}{\frac{s}{c_{n 2}}+\frac{1}{I_{n 2} s}}}}+\cdots+\frac{1}{\frac{s}{c_{2 n}}+\frac{1}{I_{2 n} s+\cdots+\frac{s}{\frac{c}{c_{n n}}+\frac{1}{I_{n n} s}}}},
$$

where: $I_{i}, I_{i i}\left[\mathrm{kgm}^{2}\right], i=1,2, \cdots, n$-values of determined mass moments of inertia of the inertial elements of the searched drive system; $c_{i}, c_{i i}[\mathrm{Nm} / \mathrm{rad}], i=1,2, \cdots, n$-values of determined coefficients of stiffness of elastic elements of the searched drive system.

A set of the determined values of dynamic parameters should be treated as "a representative" of possible solutions. An application of synthesis enables to obtain an infinitive set of these parameters within the framework of one established structure and assumed dynamic properties. To reach this objective the dimensionless coefficient of proportionality $H$ is introduced into the analyzed characteristics of slowness. It enables to determine an infinitive set of solutions of dynamic parameters in relation to the assumed dynamic properties. An introduction of the proportionality coefficient in the case of the slowness under consideration, in the form of the chain fraction, Equation (4), will cause that it will have the form as follows:

$$
H U(s)=H I_{1} s+\frac{1}{\frac{s}{H c_{1}}+\frac{1}{H I_{2} s+\cdots+\frac{s}{H c_{n-1}+\frac{1}{H I_{n} s}}}},
$$

where: $\mathrm{HI}_{i}$ - the set of mass moments of inertia dependent on the value of the coefficient of proportionality; $\mathrm{Hc}_{\mathrm{i}-1}$-the set of stiffness of elastic elements, dependent on the value of the coefficient of proportionality; $H \in(0, \infty) ; i=1,2, \cdots, n$.

In the result of the conducted synthesis of slowness, Equation (3) is a discrete vibrating system, presented in Figure 1, corresponding to the function from the relationship in Equation (4) and a vibrating system, presented in Figure 2 as an interpretation of the relationship, Equation (6), are obtained. Additionally, in Figure 1, an inertial element on which the input signal (forcing moments) and the output signal (angular velocity), in relation to which the characteristics of slowness, Equation (3), are defined and presented. Such models reflect the equivalent system in which all the shafts have the same angular velocity, equal to the speed of the primary shaft. Moreover, the mass moments of inertia of the discs, approximating toothed gears, sum up the reduced moments of inertia of meshing gears-assuming perfectly rigidness of the gear teeth. 


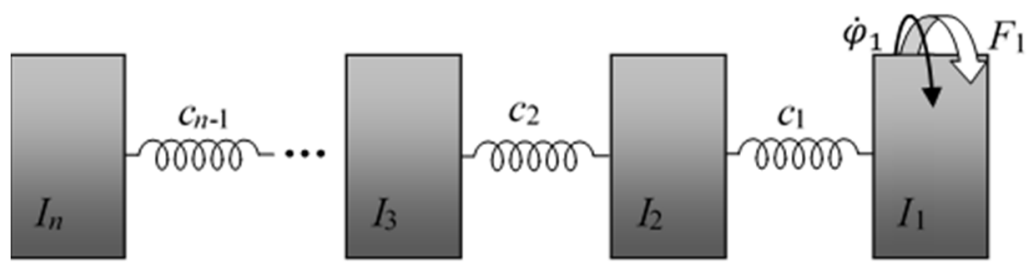

Figure 1. Cascade structure of the free drive system.

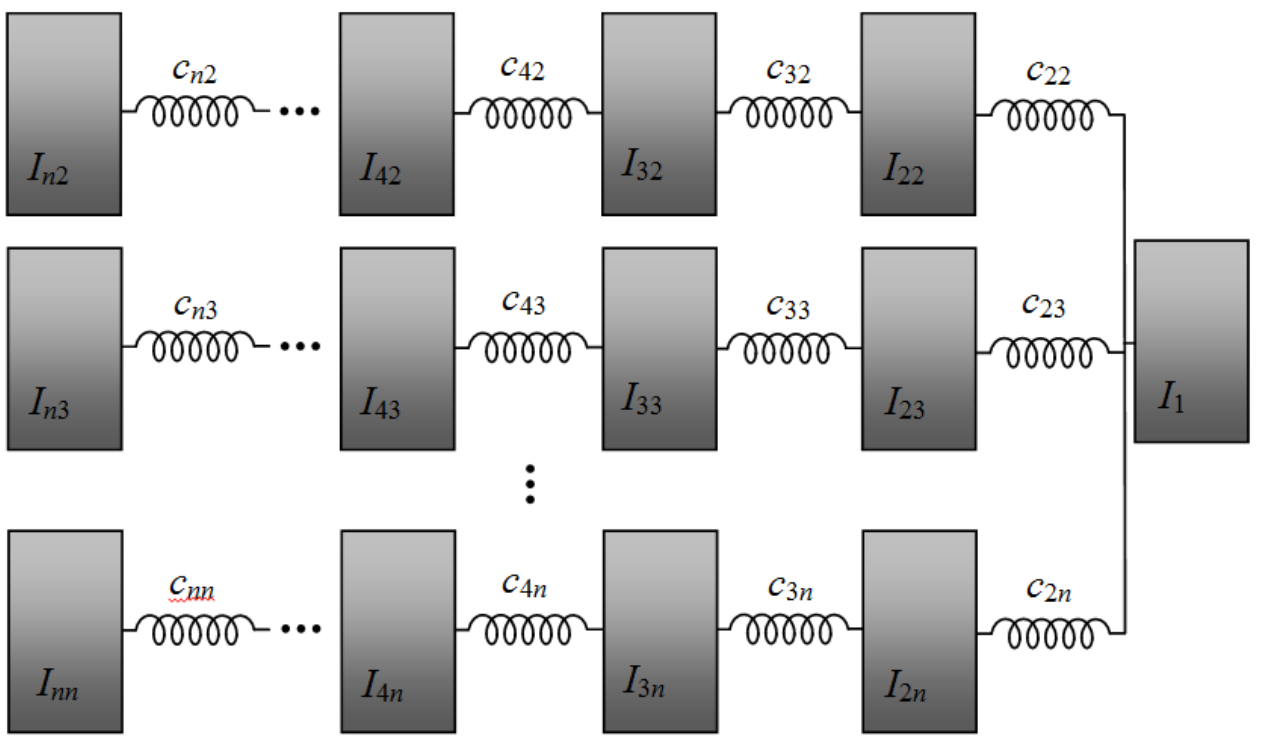

Figure 2. Cascade-branched of the free drive system.

A determination of the primary system structure, assuming that the kinetic and potential energy of the reduced system and the primary system are the same, and do not give an unambiguous solution. For this purpose, an additional condition is introduced, stating that all subsystems of the primary system should meet the expected dynamic requirements of the selected, assumed resonance frequencies.

Considering the cascade model of the drive system given in Figure 1, the synthesis of the subsystems of the primary system begins with decoupling the system into two subsystems in relation to the reduced inertial component $I_{2}$ and determining the frequency of anti-resonant subsystems decoupled in relation to the considered inertial component. For this purpose, based on the determined parameters of the synthesized structure of the system (Figure 1), the dynamic stiffness matrix, $Z(s)[25,26]$, is built in the following form:

$$
\mathbf{Z}(s)=\left[\begin{array}{cccc}
Z_{11} & Z_{12} & \cdots & Z_{1 n} \\
Z_{21} & Z_{22} & \cdots & Z_{2 n} \\
\vdots & \vdots & & \vdots \\
Z_{n 1} & Z_{n 2} & \cdots & Z_{n n}
\end{array}\right]=\left[\begin{array}{cccc}
I_{1} s^{2}+c_{1} & -c_{1} & \cdots & 0 \\
-c_{1} & I_{2} s^{2}+c_{1}+c_{2} & \cdots & 0 \\
\vdots & \vdots & & \vdots \\
0 & 0 & \cdots & I_{n} s^{2}+c_{n-1}
\end{array}\right] .
$$

Based on the dynamic stiffness matrix, the algebraic complement $M_{22}(s)$ is determined with respect to the inertial element, $I_{2}$, of the reduced drive system, obtained in the result of synthesis in the following form:

$$
M_{22}(s)=D_{22}(Z)=(-1)^{2+2}\left|Z_{22}\right| .
$$

Using the relationships shown in Equations (7) and (8), the following slowness function is determined:

$$
U_{1}(s)=\frac{s \operatorname{det} Z(s)}{M_{22}(s)} \Rightarrow U_{1}(s)=\frac{s\left(s^{2}+\omega_{b 1}^{2}\right)\left(s^{2}+\omega_{b 2}^{2}\right) \cdots\left(s^{2}+\omega_{b n}^{2}\right)}{\left(s^{2}+\omega_{2 z 1}^{2}\right)\left(s^{2}+\omega_{2 z 2}^{2}\right) \cdots\left(s^{2}+\omega_{2 z(n-1)}^{2}\right)},
$$

where: $\omega_{b 1}<\omega_{b 2}<\cdots<\omega_{b n}, \omega_{2 z 1}<\omega_{2 z 2}<\cdots<\omega_{2 z(n-1)}$. 
Taking the highest values of the resonance and anti-resonance frequencies from the slowness function, Equation (9), the dynamic characteristics of the searched primary system on the first shaft of the multi-stage drive system, are built. The function constructed in this way is synthesized by the method of decomposing the characteristic into a continued fraction to determine the parameters of the primary system on the first shaft (described by the stiffness coefficient $c_{1}$ ):

$$
U_{1} \prime(s)=H_{1} \frac{s\left(s^{2}+\omega_{b n}^{2}\right)}{\left(s^{2}+\omega_{2 z(n-1)}^{2}\right)}=H_{1} I_{(2) 1} s+\frac{1}{\frac{s}{H_{1} c_{(1) 1}}+\frac{1}{H_{1} I_{(1) 1} s}},
$$

where: $I_{(1) 1}, I_{(2) 1}\left[\mathrm{kgm}^{2}\right]$-mass moments of inertia of the synthesized inertial components, $c_{11}[\mathrm{Nm} / \mathrm{rad}$ stiffness coefficient of the synthesized elastic element, $H_{1}$-dimensionless factor of proportionality.

In order to make the obtained dynamic parameters of the system consistent with the parameters of the reduced system, the coefficient of proportionality $H_{1}$ should be determined. The coefficient of proportionality is determined so that the following condition is met:

$$
H_{1} I_{(1) 1}=I_{1} \Rightarrow H_{1}=\frac{I_{1}}{I_{(1) 1}}
$$

and the function $U_{1} \prime(s)$ takes the following form:

$$
U_{1} \prime(s)=I_{2 \prime} s+\frac{1}{\frac{s}{c_{1}}+\frac{1}{I_{1} s}},
$$

where: $I_{2 \prime}=H_{1} I_{(2) 1}, I_{1}=H_{1} I_{(1) 1}, c_{1}=H_{1} c_{(1) 1}$.

The determined values of the above coefficients of the component corresponds to the searched parameters of the primary system on the first shaft of the multi-stage drive system. As a result of designing the structure and parameters of the primary system, the structure of the system was decoupled into two subsystems (see Figure 3).

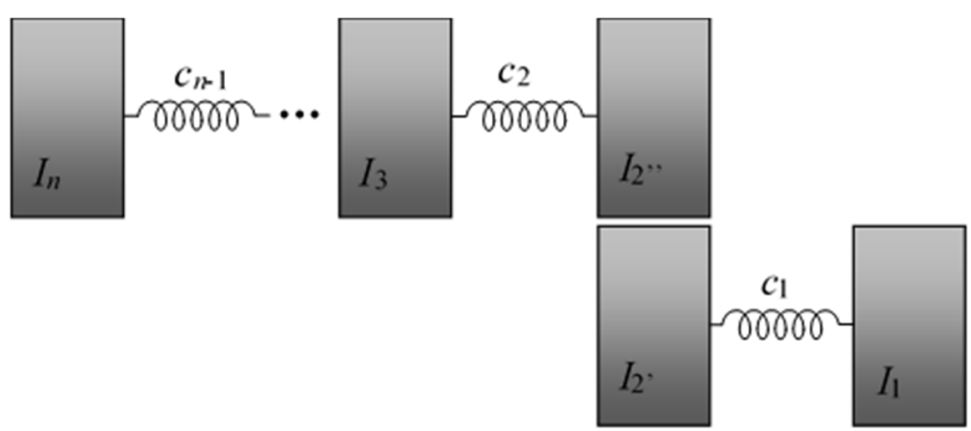

Figure 3. Model of the drive system including the first decoupling.

The subsystem, whose dynamic parameters have the following values, was taken for a further synthesis:

$$
I_{2 \prime \prime}=I_{2}-H_{1} I_{(2) 1}, c_{2}, \cdots, c_{n-1}, I_{n}
$$

The dynamic stiffness matrix of the analyzed subsystem is:

$$
Z_{1}(s)=\left[\begin{array}{cccc}
Z_{22 \prime \prime} & Z_{23} & \cdots & Z_{2 n} \\
Z_{32} & Z_{33} & \cdots & Z_{3 n} \\
\vdots & \vdots & & \vdots \\
Z_{n 2} & Z_{n 2} & \cdots & Z_{n n}
\end{array}\right]=\left[\begin{array}{cccc}
I_{2 \prime \prime} s^{2}+c_{2} & -c_{2} & \cdots & 0 \\
-c_{2} & I_{3} s^{2}+c_{2}+c_{3} & \cdots & 0 \\
\vdots & \vdots & & \vdots \\
0 & 0 & \cdots & I_{n} s^{2}+c_{n-1}
\end{array}\right] \text {, }
$$

and an algebraic complement to an inertial element of the stiffness matrix is:

$$
M_{33}(s)=D_{33}(Z)=(-1)^{2+2}\left|Z_{33}\right| .
$$


Using the relationships in Equations (14) and (15), the following slowness function is determined:

$$
U_{2}(s)=\frac{s \operatorname{det} Z_{1}(s)}{M_{33}(s)} \Rightarrow U_{2}(s)=\frac{s\left(s^{2}+\omega_{1 b 1}^{2}\right)\left(s^{2}+\omega_{1 b 2}^{2}\right) \cdots\left(s^{2}+\omega_{1 b n}^{2}\right)}{\left(s^{2}+\omega_{3 z 1}^{2}\right)\left(s^{2}+\omega_{3 z 2}^{2}\right) \cdots\left(s^{2}+\omega_{3 z(n-1)}^{2}\right)} .
$$

The parameters of the searched primary system on the second shaft of the multi-stage driving system, assuming the maximum resonant frequency of slowness, Equation (3), and anti-resonant slowness, Equation (16), are obtained from the following relationship:

$$
U_{2} \prime(s)=H_{2} \frac{s\left(s^{2}+\omega_{b n}^{2}\right)}{\left(s^{2}+\omega_{3 z(n-1)}^{2}\right)}=H_{2} I_{(3) 2} s+\frac{1}{\frac{s}{H_{2} c_{(2) 2}}+\frac{1}{H_{2} I_{(2) 2} s}},
$$

where: $I_{(2) 2}, I_{(3) 2}\left[\mathrm{kgm}^{2}\right]$-mass moments of inertia of the synthesized inertial components, $c_{(2) 2}[\mathrm{Nm} / \mathrm{rad}]$-stiffness coefficient of the synthesized elastic element.

Based on the calculated parameters, the following coefficient of proportionality $\mathrm{H}_{2}$ is determined:

$$
H_{2}=\frac{I_{2 \prime \prime}}{I_{(2) 2}}
$$

which allows us to determine the parameters of the subsystem on the second shaft of the primary system (described by the stiffness $c_{2}$ ):

$$
I_{2 \prime \prime}=H_{2} I_{(2) 2}, I_{3 \prime}=H_{2} I_{(3) 2}, c_{2}=H_{2} c_{(2) 2},
$$

and the subsystem parameters for further analysis:

$$
I_{3 \prime \prime}=I_{3}-H_{2} I_{(3) 2}, c_{3}, \cdots, c_{n-1}, I_{n} .
$$

As the result of this step, the structure of the system was obtained, which included the first and second decoupling, shown in Figure 4.

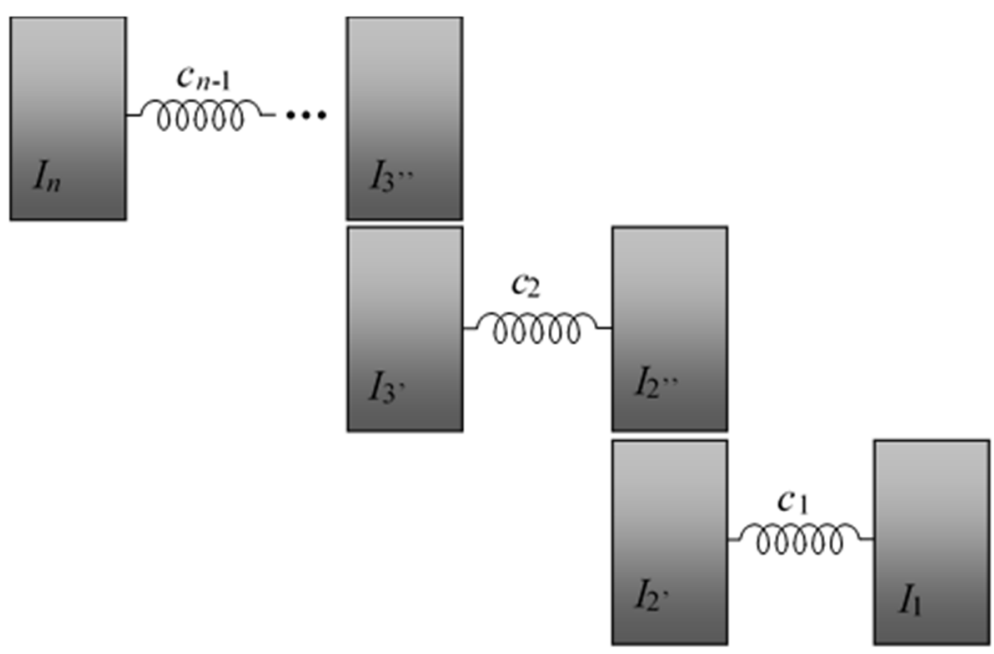

Figure 4. Model of the drive system including the first and the second decoupling.

The process describes by the relationships (7-20) is continued until the system is decoupled in relation to the inertial element $I_{n-1}$.

To couple the obtained primary systems to each shaft of the multi-stage drive system, the requirements for the total gear ratio of such a system should be assumed. This gear ratio is the product of the selected single gear ratios on each gear stage and is expressed with the following relationship: $c_{\mathrm{n}-1}$

$$
i_{1 k}=\prod_{i=1}^{k-1} i_{i, i+1}
$$

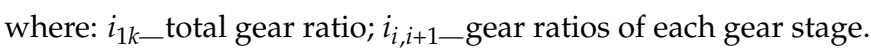


To obtain real parameters of the synthesized gear, the gear ratio, Equation (21), should be taken into account. This is done by multiplying the obtained parameters of the drive system, with the gear ratio selected on each stage (this applies to the case where the system is reduced to a drive member), in the form of:

mass moments of inertia:

$$
I_{1 r}=I_{1}, I_{2 / r}=I_{2 \prime}, I_{2^{\prime \prime} r}=I_{2^{\prime \prime}} i_{12}{ }^{2}, I_{3 / r}=I_{3^{\prime}} i_{12}{ }^{2}, I_{3^{\prime \prime} r}=I_{3^{\prime \prime}} i_{13}{ }^{2}, \cdots, I_{n r}=I_{n} i_{1 k}{ }^{2} ;
$$

elastic elements:

$$
c_{1 r}=c_{1}, c_{2 r}=c_{2} i_{12}{ }^{2}, \cdots, c_{(n-1) r}=c_{n-1} i_{1 k}{ }^{2} .
$$

The drive system, meeting the desired properties, shown in Figure 5 , in the form of predetermined resonance frequencies and gear ratios of each stage of the drive system, is the final result.

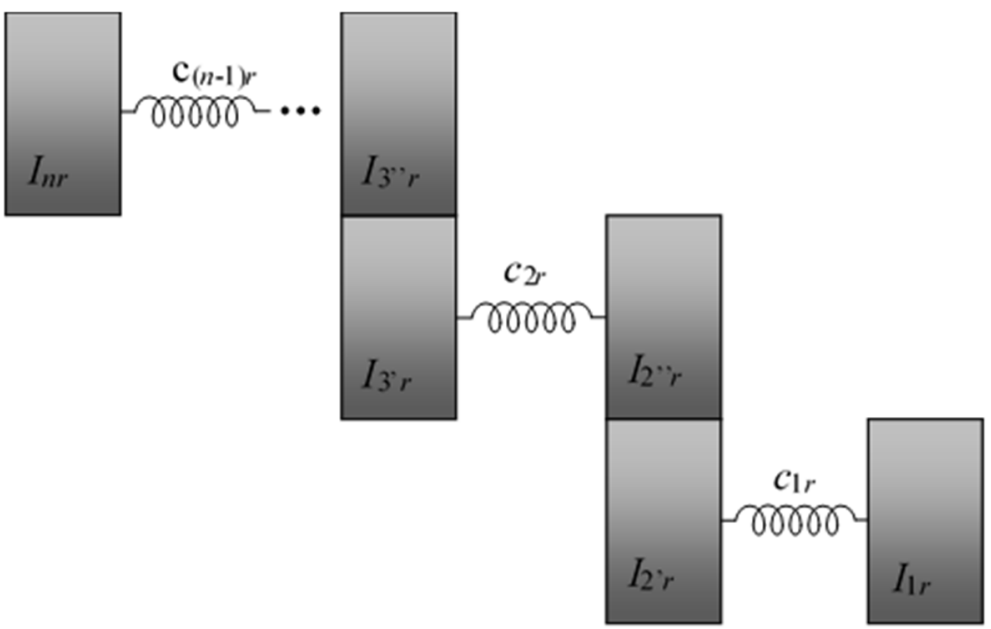

Figure 5. Model of the drive system including all the couplings.

The algorithm of the procedure allows us to determine the structures of branched multi-stage driving systems (see Figure 2), which consists of analyzing each branch separately. Therefore, considering the cascade-branched system, the first branch dynamic stiffness matrix is constructed in the following form:

$$
Z_{11}(s)=\left[\begin{array}{cccc}
Z_{11} & Z_{12} & \cdots & Z_{1 n} \\
Z_{21} & Z_{22} & \cdots & Z_{2 n} \\
\vdots & \vdots & & \vdots \\
Z_{n 1} & Z_{n 2} & \cdots & Z_{n n}
\end{array}\right]=\left[\begin{array}{cccc}
I_{1} s^{2}+c_{22} & -c_{22} & \cdots & 0 \\
-c_{22} & I_{22} s^{2}+c_{22}+c_{32} & \cdots & 0 \\
\vdots & \vdots & & \vdots \\
0 & 0 & \cdots & I_{n 2} s^{2}+c_{n 2}
\end{array}\right] .
$$

Based on the dynamic stiffness matrix, the algebraic complement $M_{22}(s)$ is determined in relation to the inertial element $\mathrm{I}_{11}$ of the reduced driving system, obtained as a result of the following synthesis:

$$
M_{22}(s)=D_{22}(Z)=(-1)^{2+2}\left|Z_{22}\right| .
$$

Using the relationships in Equations (24) and (25), the following slowness function is determined:

$$
U_{11}(s)=\frac{s \operatorname{det} Z_{11}(s)}{M_{22}(s)} \Rightarrow U_{11}(s)=\frac{s\left(s^{2}+\omega_{1 b 1}^{2}\right)\left(s^{2}+\omega_{1 b 2}^{2}\right) \cdots\left(s^{2}+\omega_{1 b n}^{2}\right)}{\left(s^{2}+\omega_{2 z 1}^{2}\right)\left(s^{2}+\omega_{2 z 2}^{2}\right) \cdots\left(s^{2}+\omega_{2 z(n-1)}^{2}\right)},
$$

where: $\omega_{1 b 1}<\omega_{1 b 2}<\cdots<\omega_{1 b n}, \omega_{1 z 1}<\omega_{1 z 2}<\cdots<\omega_{1 z j}$.

The parameters of searched primary system on the first shaft, assuming the maximum frequencies: the resonant primary slowness characteristics, Equation (3), and the chosen on anti-resonant slowness frequency, Equation (26), are obtained from the following relationship:

$$
U_{11} \prime(s)=\frac{s\left(s^{2}+\omega_{b n}^{2}\right)}{\left(s^{2}+\omega_{2 z j}^{2}\right)}=H_{11} I_{(22) 1} s+\frac{1}{\frac{s}{H_{11} c_{(22) 1}}+\frac{1}{H_{11} I_{(1) 1} s}},
$$


where: $I_{(22) 1}, I_{(1) 1}\left[\mathrm{kgm}^{2}\right]$ —synthesized mass moments of inertia of inertial components; $c_{(22) 1}$ $[\mathrm{Nm} / \mathrm{rad}]$ - synthetized stiffness coefficient of elastic component.

The parameters, from which the factor of proportionality $H_{11}$ is determined to decide about a selection of the anti-resonance frequency obtained on the basis of Equation (27):

$$
H_{11}=\frac{I_{1}}{I_{(1) 1}} .
$$

The coefficient $H_{11}$ enables to determine the parameters of the system on the first shaft i.e.:

$$
I_{22 \prime}=H_{11} I_{(22) 1}, I_{1}=H_{11} I_{(1) 1}, c_{(2) 2}=H_{11} c_{(22) 1}
$$

As well as the parameters of the system for a further synthesis:

$$
I_{22^{\prime \prime}}=I_{22}-H_{11} I_{(22) 1}, c_{32}, \cdots, c_{n 2}, I_{n 2}
$$

As a result of this step, the structure of the system was obtained, taking into account the first decoupling shown in Figure 6.

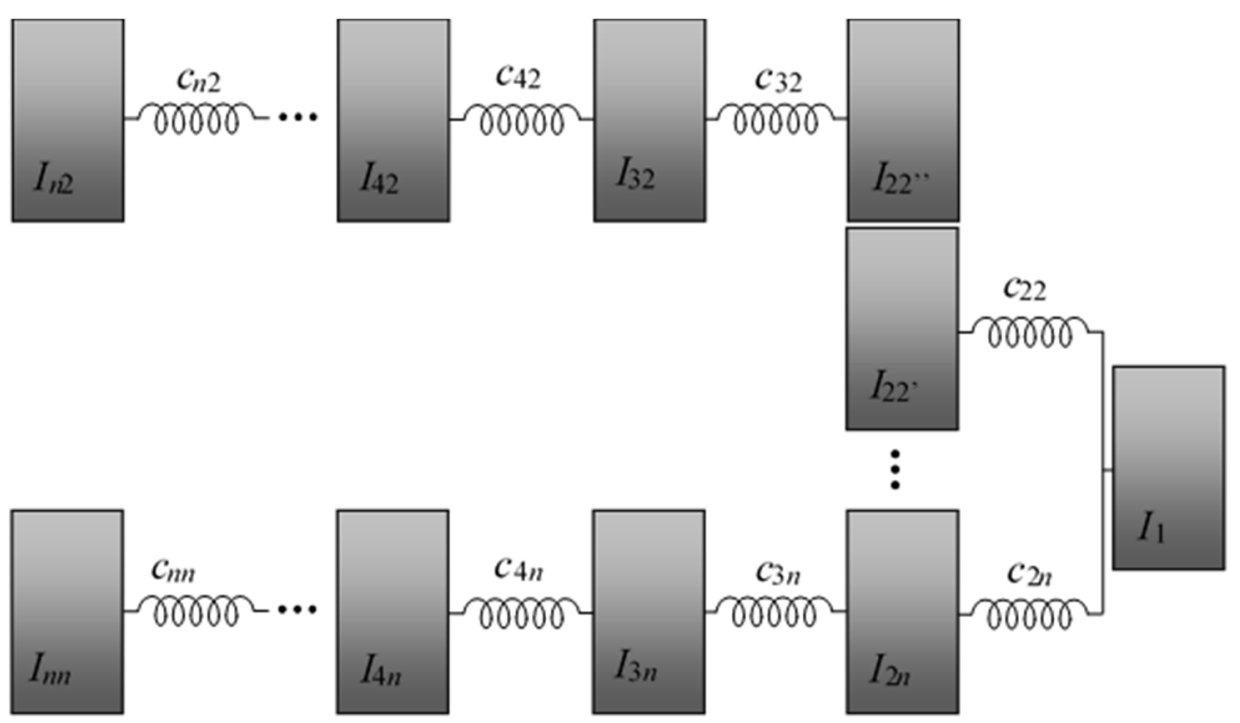

Figure 6. Model of the drive system including the first decoupling.

The process described by Equations (24)-(30) is continued until decoupling of the subsystem in relation to the inertial component $I_{(n-1) 2}$. The implemented algorithm should be repeated for the remaining branches of the system. By applying this method, all the branches of the synthesized system are decoupled. In order to couple the sub-systems and obtain the real parameters of the synthesized gearbox, the following ratios at each branch of the system should be taken into account:

$$
i_{1 k}^{n-1}=\prod_{i=1}^{k-1} i_{i, i+1}^{n-1} .
$$

where: $i_{1 k}^{n-1}$ - total gear ratio in the branch $n-1, i_{i, i+1}^{n-1}$-gear ratio at the successive gear stage in the branch $n-1$.

After multiplying the parameters of the drive system, with the selected gear ratio at each stage in the following form:

- $\quad$ the mass moments of inertia:

$$
\begin{aligned}
& I_{1 r}=I_{1}, I_{2 n^{\prime} r}=I_{2 n^{\prime}}, I_{2 n^{\prime \prime} r}=I_{2 n^{\prime \prime}}\left(i_{12}^{n-1}\right)^{2}, I_{3 n^{\prime} r}=I_{3 n^{\prime}}\left(i_{12}^{n-1}\right)^{2}, \\
& I_{3 n^{\prime \prime} r}=I_{3 n^{\prime \prime}}\left(i_{13}^{n-1}\right)^{2}, \cdots, I_{n n r}=I_{n n}\left(i_{1 k}^{n-1}\right)^{2} ;
\end{aligned}
$$


- $\quad$ the elastic components:

$$
c_{2 n r}=c_{2 n}, c_{3 n r}=c_{3 n}\left(i_{12}^{n-1}\right)^{2}, \cdots, c_{n n r}=c_{n n}\left(i_{1 k}^{n-1}\right)^{2},
$$

The system presented in Figure 7 is obtained.

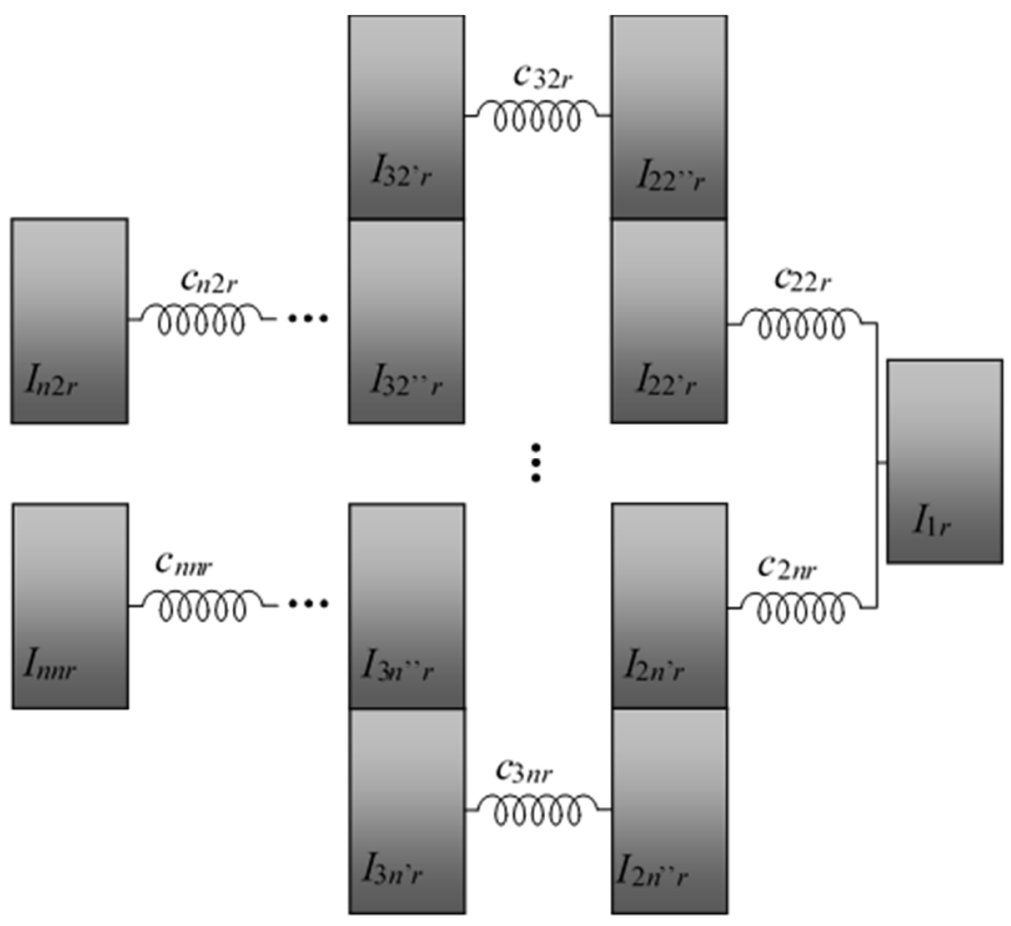

Figure 7. Model of the drive system including all the couplings.

The synthesis methods for the creation of torsionally vibrating discrete structures are presented in this chapter. These structures consist of non-deformable discs with one degree of freedom, connected to each other by weightless shaft sections. Non-deformable discs model the components such as gears, pulleys, flywheels, as well as clutches, etc., mounted on the shaft, i.e., the components whose outer diameters are larger than the shaft diameter. The mass moments of inertia of the shaft sections between the discs may also be the elements of the non-deformable discs.

The use of the presented methods of synthesis allows us to obtain both the sequence of structures and the parameters of the required components of inertial and elastic type, meeting the same dynamic properties. The methods of synthesis, discussed in this chapter, determine the structure and dynamic parameters of the synthesized system. The structures and parameters, obtained in this way, can be the basis for the optimal—in terms of designing process (identification)—selection of driving systems. However, it should be emphasized that the torsional vibration models, obtained by the synthesis method, can be used in the designing stage, as a tool for a preliminary estimation of dynamic properties. This condition especially applies to the stage of conceptual and preliminary design, when the real object is missing. At the designing stage, when the final structural shape of the drive is known, the synthesis results should be verified by testing.

\section{Numerical Analysis}

A numerical example of the structural and parametric synthesis of a drive system is presented. The searched driving system has six degrees of freedom, consisting of a power element (motor) and a two-speed gearbox (see Figure 8). The gearbox is to work in specific resonance zones, i.e., to meet the required dynamic properties i.e., required resonance frequencies. The resonance frequencies should be selected so that the drive system operates out of this range. The data, such as the frequency of the drive system, was taken from the work [27], in which the condition of wind turbine gearboxes under changing operating conditions was analyzed. The following parameters of resonance frequencies were adopted:

$$
f_{b 1}=0 \mathrm{~Hz}, f_{b 2}=352 \mathrm{~Hz}, f_{b 3}=705 \mathrm{~Hz}, f_{b 4}=1056 \mathrm{~Hz}, f_{b 5}=1410 \mathrm{~Hz}, f_{b 6}=2115 \mathrm{~Hz} .
$$




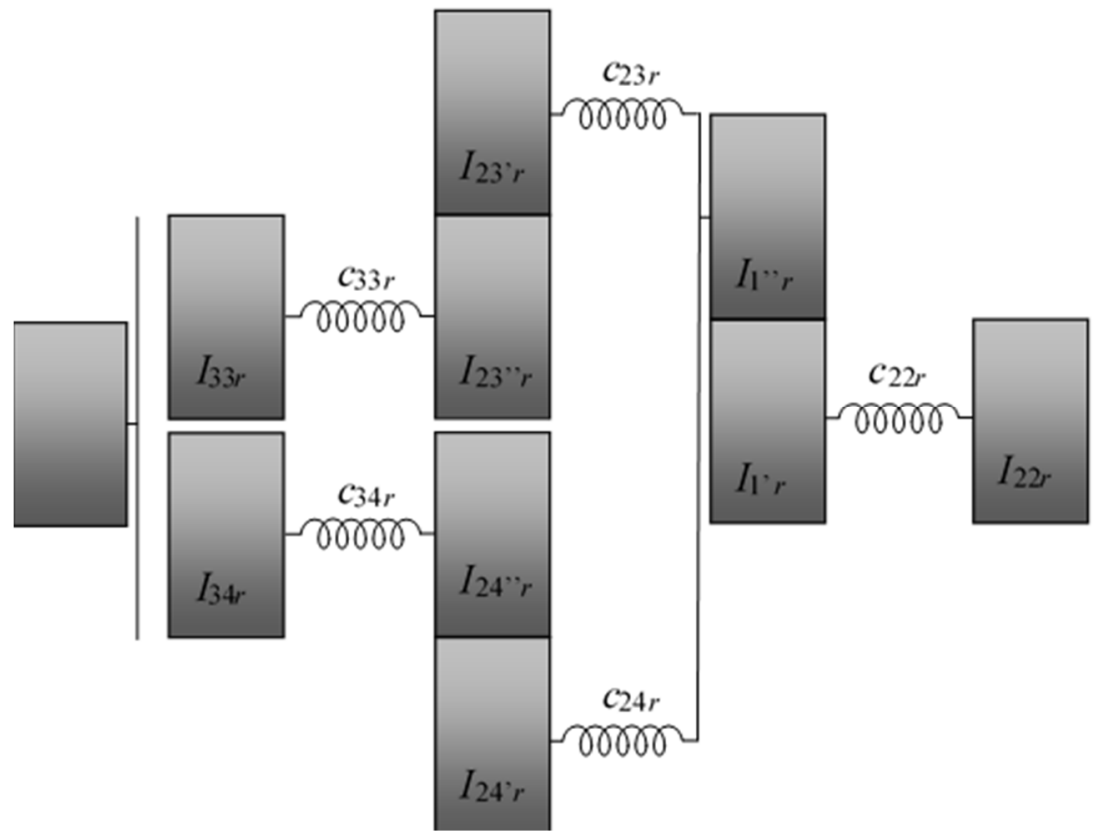

Figure 8. Model of the drive system including all the couplings.

The required dynamic properties of the tested system should be presented in an analytical form. The analytical form involves a determination of the dynamic characteristic in the form of a measurable function, describing the required system. Moreover, it is assumed that the function is determined in relation to the inertia of the input-output signal from the gearbox driving shaft:

$$
U(s)=\frac{1}{V(s)}=\frac{1}{s Y(s)}=H \frac{\prod_{i=1}^{6}\left(s^{2}+\omega_{b i}{ }^{2}\right)}{s \prod_{i=1}^{5}\left(s^{2}+\omega_{z i}{ }^{2}\right)} .
$$

For this purpose, on the basis of the adopted resonance frequencies $\omega_{b i}=2 \pi f_{b i}$, the antiresonance frequencies, $\omega_{z i}$ are calculated, which are the roots of the polynomial determined according to the following relationship:

$$
s \prod_{i=1}^{n-1}\left(s^{2}+\omega_{z i}^{2}\right)=\frac{1}{2 n} \frac{d}{d s} \prod_{i=1}^{n}\left(s^{2}+\omega_{b i}^{2}\right) .
$$

Then, the required dynamic properties of the searched system assume the following sequence of frequencies:

- $\quad$ the resonance:

$$
\begin{gathered}
\omega_{b 1}=0 \mathrm{rad} / \mathrm{s}, \omega_{b 2}=2.212 \mathrm{e} 3 \mathrm{rad} / \mathrm{s}, \omega_{b 3}=4.43 e 3 \mathrm{rad} / \mathrm{s}, \\
\omega_{b 4}=6.635 \mathrm{e} 3 \mathrm{rad} / \mathrm{s}, \omega_{b 5}=8.86 e 3 \mathrm{rad} / \mathrm{s}, \omega_{b 6}=1.329 e 4 \mathrm{rad} / \mathrm{s},
\end{gathered}
$$

- $\quad$ the and anti-resonance:

$$
\begin{gathered}
\omega_{z 1}=1.151 \mathrm{e} 3 \mathrm{rad} / \mathrm{s}, \omega_{z 2}=3.46 \mathrm{e} 3 \mathrm{rad} / \mathrm{s}, \omega_{z 3}=3.46 \mathrm{e} 3 \mathrm{rad} / \mathrm{s}, \\
\omega_{z 4}=8.136 \mathrm{e} 3 \mathrm{rad} / \mathrm{s}, \omega_{z 5}=1.233 \mathrm{e} 4 \mathrm{rad} / \mathrm{s} .
\end{gathered}
$$

With regard to the dynamic characteristics in Equation (34), on the basis of the adopted resonance and anti-resonance frequencies, it is necessary to determine the dynamic parameters of the required model of the drive system. For this purpose, the characteristics in Equation (34) should be decomposed by the mixed synthesis method, to obtain the following sum of the continued fractions:

$$
U(s)=I_{1} s+\frac{1}{\frac{s}{c_{22}}+\frac{1}{I_{22} s}}+\frac{1}{\frac{s}{c_{23}}+\frac{1}{I_{23} s+\frac{s}{\frac{s}{c_{33}}+\frac{1}{I_{33} s}}}}+\frac{1}{\frac{s}{c_{24}}+\frac{1}{I_{24} s+\frac{s}{c_{34}}+\frac{1}{I_{34} s}}} .
$$


As the result of the mixed synthesis method, the characteristic function, Equation (36), allows us to obtain a series of parameters of the elastic and inertial components of the system structure, which is presented in Figure 9.

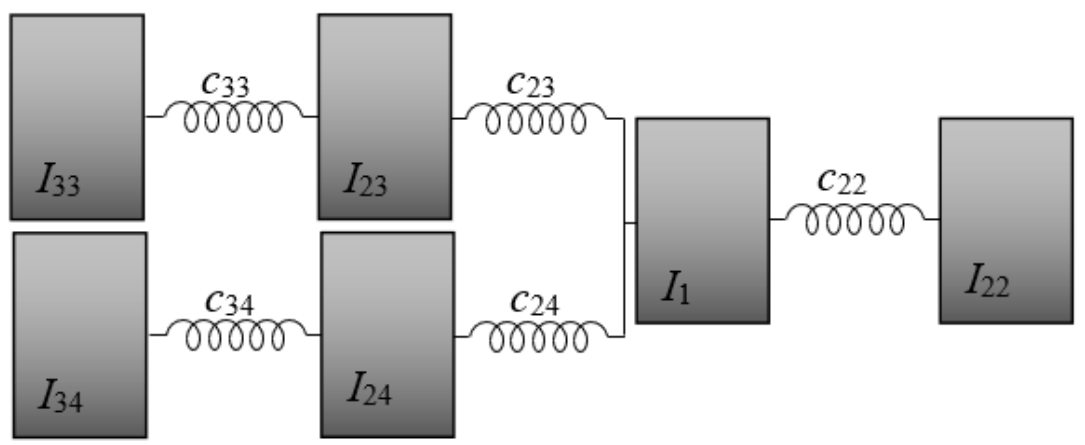

Figure 9. The cascade-branched structure of the drive system.

In the case of the three-branched structure of the system (Figure 9), the sets of dynamic parameters were obtained in relation to the synthesized cascade-branched structure. The number of possible cases, different sets of parameters, depends on the number of degrees of freedom of the required system and the number of branches $[11,12]$. The parameters for each case are presented in Tables 1 and 2.

Table 1. Parameters of inertial components.

\begin{tabular}{ccccccc}
\hline & $\begin{array}{c}\boldsymbol{I}_{1} \\
{\left[\mathbf{k g m}^{2}\right]}\end{array}$ & $\begin{array}{c}\mathbf{I}_{22} \\
{\left[\mathbf{k g m}^{2} \mathbf{]}\right.}\end{array}$ & $\begin{array}{c}\mathbf{I}_{23} \\
{\left[\mathbf{k g m}^{2}\right]}\end{array}$ & $\begin{array}{c}\mathbf{I}_{33} \\
{\left[\mathbf{k g m}^{2}\right]}\end{array}$ & $\begin{array}{c}\mathbf{I}_{24} \\
{\left[\mathbf{k g m}^{2} \mathbf{]}\right.}\end{array}$ & $\begin{array}{c}\boldsymbol{I}_{34} \\
{\left[\mathbf{k g m}^{2}\right]}\end{array}$ \\
\hline 1 & 1 & 8.5691 & 0.9575 & 0.2717 & 0.2126 & 0.0343 \\
2 & 1 & 8.5691 & 0.5509 & 0.5033 & 0.2562 & 0.1657 \\
3 & 1 & 8.5691 & 0.2928 & 0.7471 & 0.3886 & 0.0476 \\
4 & 1 & 0.9236 & 1.3116 & 7.5631 & 0.2126 & 0.0343 \\
5 & 1 & 0.9236 & 0.6809 & 8.0188 & 0.2562 & 0.1657 \\
6 & 1 & 0.9236 & 0.3119 & 8.3736 & 0.3886 & 0.0476 \\
7 & 1 & 0.3056 & 3.4067 & 6.0860 & 0.2126 & 0.0343 \\
8 & 1 & 0.3056 & 0.6809 & 8.0188 & 0.2928 & 0.7471 \\
9 & 1 & 0.3056 & 0.3119 & 8.3736 & 0.5509 & 0.5033 \\
10 & 1 & 0.1306 & 3.4067 & 6.0860 & 0.2562 & 0.1657 \\
11 & 1 & 0.1306 & 1.3116 & 7.5631 & 0.2928 & 0.7471 \\
12 & 1 & 0.1306 & 0.3119 & 8.3736 & 0.9575 & 0.2717 \\
13 & 1 & 0.1163 & 3.4067 & 6.0860 & 0.3886 & 0.0476 \\
14 & 1 & 0.1163 & 1.3116 & 7.5631 & 0.5509 & 0.5033 \\
15 & 1 & 0.1163 & 0.6809 & 8.0188 & 0.9575 & 0.2717 \\
\hline
\end{tabular}


Table 2. Parameters of elastic components.

\begin{tabular}{cccccc}
\hline & $\begin{array}{c}\boldsymbol{c}_{22} \\
{[\mathbf{N m} / \mathbf{r a d}]}\end{array}$ & $\begin{array}{c}\boldsymbol{c}_{23} \\
{[\mathbf{N m} / \mathbf{r a d}]}\end{array}$ & $\begin{array}{c}c_{33} \\
{[\mathbf{N m} / \mathbf{r a d}]}\end{array}$ & $\begin{array}{c}\boldsymbol{c}_{24} \\
{[\mathbf{N m} / \mathbf{r a d}]}\end{array}$ & $\begin{array}{c}\boldsymbol{c}_{34} \\
{[\mathbf{N m} / \mathbf{r a d}]}\end{array}$ \\
\hline 1 & $11,352,402$ & $21,217,541$ & $4,880,676$ & $26,328,273$ & $2,789,518$ \\
2 & $11,352,402$ & $19,703,292$ & $11,152,217$ & $27,842,522$ & $7,707,632$ \\
3 & $11,352,402$ & $28,739,226$ & $13,854,513$ & $18,806,588$ & $2,165,160$ \\
4 & $11,057,123$ & $21,512,821$ & $20,310,401$ & $26,328,273$ & $2,789,518$ \\
5 & $11,057,123$ & $19,998,572$ & $23,942,687$ & $27,842,522$ & $7,707,632$ \\
6 & $11,057,123$ & $29,034,505$ & $18,114,241$ & $18,806,588$ & $2,165,160$ \\
7 & $10,160,419$ & $22,409,525$ & $14,673,717$ & $26,328,273$ & $2,789,518$ \\
8 & $10,160,419$ & $19,998,572$ & $23,942,687$ & $28,739,226$ & $13,854,513$ \\
9 & $10,160,419$ & $29,034,505$ & $18,114,241$ & $19,703,292$ & $11,152,217$ \\
10 & $8,646,169$ & $22,409,525$ & $14,673,717$ & $2,784,252$ & $7,707,632$ \\
11 & $8,646,169$ & $21,512,821$ & $20,310,401$ & $28,739,226$ & $13,854,513$ \\
12 & $8,646,169$ & $29,034,505$ & $18,114,241$ & $21,217,541$ & $4,880,676$ \\
13 & $17,682,103$ & $22,409,525$ & $14,673,717$ & $18,806,588$ & $2,165,160$ \\
14 & $17,682,103$ & $21,512,821$ & $20,310,401$ & $19,703,292$ & $11,152,217$ \\
15 & $17,682,103$ & $19,998,572$ & $23,942,687$ & $21,217,541$ & $4,880,676$ \\
\hline
\end{tabular}

In relation to the determined inertial and elastic parameters of the structure of the equivalent system (shown in Figure 8), the parameters of the required drive system, from Figure 7, will be determined in relation to the set of the first 3 parameters listed in Tables 1 and 2 . In the first step, the parameters of uncoupled structures, in relation to the reduced inertial parameters $I_{1}, I_{23}$ as well as $I_{24}$ on all the branches of the equivalent system will be determined. The inertial parameters for each case are given in Table 3.

Table 3. Parameters of inertial components.

\begin{tabular}{cccc}
\hline & $\mathbf{1}$ & $\mathbf{2}$ & $\mathbf{3}$ \\
\hline$I_{1 \prime}\left[\mathrm{kgm}^{2}\right]$ & 0.0648 & 0.0648 & 0.0648 \\
$I_{1^{\prime \prime}}\left[\mathrm{kgm}^{2}\right]$ & 0.9352 & 0.9352 & 0.9352 \\
$I_{22}\left[\mathrm{kgm}^{2}\right]$ & 8.5691 & 8.5691 & 8.5691 \\
$I_{23 \prime}\left[\mathrm{kgm}^{2}\right]$ & 0.1378 & 0.1267 & 0.1970 \\
$I_{23^{\prime \prime}}\left[\mathrm{kgm}^{2}\right]$ & 0.8197 & 0.4242 & 0.0958 \\
$I_{33}\left[\mathrm{kgm}^{2}\right]$ & 0.2717 & 0.5033 & 0.7471 \\
$I_{24 \prime}\left[\mathrm{kgm}^{2}\right]$ & 0.1773 & 0.1900 & 0.1202 \\
$I_{24^{\prime \prime}}\left[\mathrm{kgm}^{2}\right]$ & 0.0353 & 0.0662 & 0.2684 \\
$I_{34}\left[\mathrm{kgm}^{2}\right]$ & 0.0343 & 0.1657 & 0.0476 \\
\hline
\end{tabular}

To obtain the real parameters of the synthesized drive system, the gear ratio at each branch should be taken into account. The following form of the ratio was assumed for calculations:

$$
i_{13}^{3}=\frac{1}{2}=i_{12}^{3} i_{23}^{3}=\frac{3}{4} \cdot \frac{2}{3}, i_{14}^{4}=2=i_{12}^{4} i_{24}^{4}=\frac{3}{4} \cdot \frac{8}{3}
$$

The real parameters of the searched drive system are given in Tables 4 and 5 . 
Table 4. Parameters of inertial components.

\begin{tabular}{cccc}
\hline & $\mathbf{1}$ & $\mathbf{2}$ & $\mathbf{3}$ \\
\hline$I_{1 / r}\left[\mathrm{kgm}^{2}\right]$ & 0.0648 & 0.0648 & 0.0648 \\
$I_{1^{\prime \prime} r}\left[\mathrm{kgm}^{2}\right]$ & 0.5261 & 0.5261 & 0.5261 \\
$I_{22 r}\left[\mathrm{kgm}^{2}\right]$ & 8.5691 & 8.5691 & 8.5691 \\
$I_{23 / r}\left[\mathrm{kgm}^{2}\right]$ & 0.0775 & 0.0713 & 0.1108 \\
$I_{23^{\prime \prime}} r\left[\mathrm{kgm}^{2}\right]$ & 0.2049 & 0.1061 & 0.0240 \\
$I_{33 r}\left[\mathrm{kgm}^{2}\right]$ & 0.0679 & 0.1258 & 0.1868 \\
$I_{24 / r}\left[\mathrm{kgm}^{2}\right]$ & 0.0997 & 0.1069 & 0.0676 \\
$I_{24^{\prime \prime}} r\left[\mathrm{kgm}^{2}\right]$ & 0.1412 & 0.2648 & 1.0736 \\
$I_{34 r}\left[\mathrm{kgm}^{2}\right]$ & 0.1372 & 0.6628 & 0.1904 \\
\hline
\end{tabular}

Table 5. Parameters of elastic components.

\begin{tabular}{cccc}
\hline & $\mathbf{1}$ & $\mathbf{2}$ & $\mathbf{3}$ \\
\hline$c_{22 r}[\mathrm{Nm} / \mathrm{rad}]$ & $11,352,402$ & $11,352,402$ & $11,352,402$ \\
$c_{23 r}[\mathrm{Nm} / \mathrm{rad}]$ & $11,934,867$ & $11,083,102$ & $16,165,814$ \\
$c_{33 r}[\mathrm{Nm} / \mathrm{rad}]$ & $1,220,169$ & $2,788,054$ & $3,463,628$ \\
$c_{24 r}[\mathrm{Nm} / \mathrm{rad}]$ & $14,809,653$ & $15,661,418$ & $10,578,706$ \\
$c_{34 r}[\mathrm{Nm} / \mathrm{rad}]$ & $11,158,072$ & $30,830,524$ & $8,660,636$ \\
\hline
\end{tabular}

The obtained parameters of the driving system (Figure 8) meet the required dynamic properties and are equivalent to the determined dynamic characteristics in the form of dynamic flexibility presented in Figure 10.

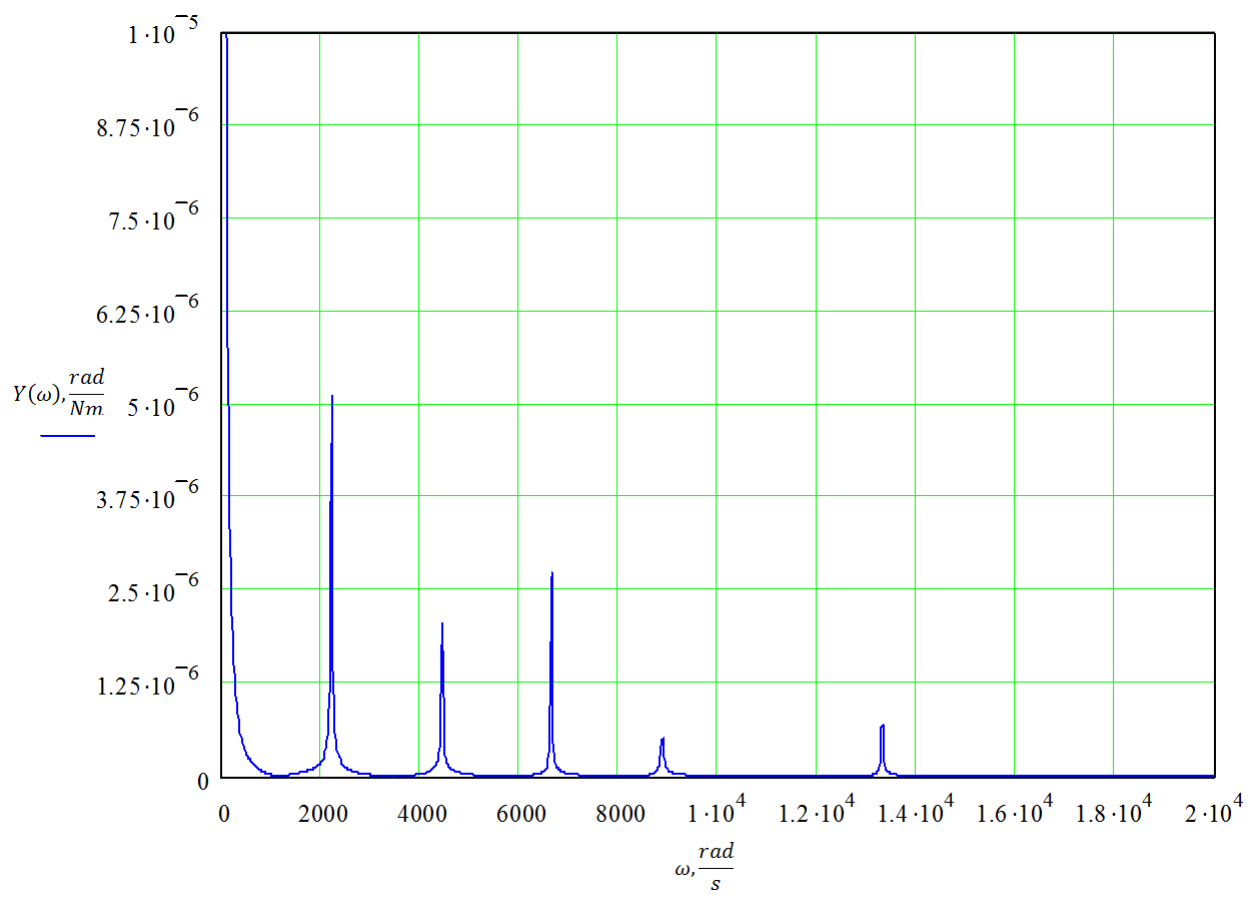

Figure 10. Dynamic characteristics (dynamic flexibility of the system obtained in the result of synthesis).

The synthesis of the drive systems showed how large the set of obtained dynamic parameters from one sequence of the required dynamic properties is. Each determined set of a dynamic parameter is treated as "representative" of possible solutions. A correct introduction of the coefficient of proportionality, $H$, depending on the experience of the designer, allows us to obtain the optimal dynamic parameters of the synthesized structure of the driving system. However, it should be emphasized that the obtained solution, which is the structure of the drive system, together with a set of dynamic parameters, should be 
used in the designing process as a tool for a preliminary estimation of dynamic properties and, if possible, subjected to experimental verification.

\section{Conclusions}

In this publication, the authors' method for searching the structure and dynamic parameters of drive systems, in relation to the assumed spectrum of free vibrations and the required ratio of the gearbox incorporated in the system, is presented. The discussed structures, vibrating torsionally as well as of the values of inertial and elastic elements of multi-degree drive systems. The presented algorithms of synthesis enable a designer to conduct a very rapid assessment of the parameters and structure of the system in the scope of the required frequencies of free vibrations. Simultaneously, an easiness of algorithmization of the discussed methods enables automation of determining the searched parameters and structure of the drive system. The drive structures, obtained in the result of synthesis, and the values of parameters related to them, can be the basis of an optimum selection in the aspect of drive systems designing. However, it should be highlighted that the models of torsional vibrations, obtained as a result of applying the synthesis method which can be used in the designing process as tools for preliminary design when a real object is absent. At the stage of construction designing, when the final design form of the drive is known, the obtained results of synthesis should be subject to experimental verification. Optimization of parameters is not the only advantage method of the applied synthesis method of the drive system. The described application can consist of the identification of parameters based on the spectrum of frequencies and the phenomenological model e.g., for diagnostic purposes of such systems.

Based on the synthesis method, formalized in this work, a search of the structure and parameters of the drive system, in the case of assumed in advance frequencies of free vibrations of the searched system, was conducted. The assumed dynamic values in the form of a slowness function were subject to a distribution with the use of a mixed synthesis method to determine a sequence of sets of parameters of the searched substitute system. An advantage of such an approach is a receipt of a set of dynamic parameters of the drive system. Already at this stage of synthesis, the designer can conduct optimization of parameters in the aspect of any criterion. In the case of the obtained branched structure and the assumed ratio of the gearbox, which is searched for as the system is to meet, a set of inertial and elastic parameters, meeting not only the required dynamic properties in the form of frequency of free vibrations but also the required ratio of the two-speed gearbox incorporated in the searched drive system, was determined. In the result of the synthesis, conducted in such a way, the designer obtains the structure and the set of parameters, on the basis of which, they can determine geometrical properties of the gearbox and then they can conduct their optimization e.g., in the aspect of the assumed criterion of minimum weight for a priori assumed values of free vibrations frequencies of the system and of the ratio, which forms the basis of classic designing of drive systems.

Author Contributions: Conceptualization, T.D. and A.D.; methodology, T.D., A.D., and L.O.; software, J.M. and D.G.; validation, J.M., D.G., and K.L.; formal analysis, A.D.; investigation, T.D. and L.O.; resources, A.D. and J.M.; data curation, J.M. and D.G.; writing—original draft preparation, T.D. and A.D.; writing—review and editing, J.M., L.O., K.L., and D.G.; visualization, J.M., L.O., and K.L. All authors have read and agreed to the published version of the manuscript.

Funding: This research received no external funding.

Institutional Review Board Statement: Not applicable.

Informed Consent Statement: Not applicable.

Data Availability Statement: Not applicable.

Conflicts of Interest: The authors declare no conflict of interest. 


\section{References}

1. De Souza, S.L.T.; Caldas, I.L.; Balthazar, J.M.; Brasil, R.M.L.R.F. Analysis of regular and irregular dynamics of a non-ideal gear rattling problem. J. Braz. Soc. Mech. Sci. 2002, 24, 1-7. [CrossRef]

2. Bozca, M.; Fietkau, P. Empirical model based optimization of gearbox geometric design parameters to reduce rattle noise in an automotive transmission. Mech. Mach. Theory 2010, 45, 1599-1612. [CrossRef]

3. Chen, T.; Zhu, R.-P.; Xiong, Y.-P.; Jin, G.-H. Analysis on natural characteristics of four-stage main transmission system in three-engine helicopter. Vibroeng. Proc. 2017, 12, 19-23.

4. Parker, R.G.; Agashe, V.; Vijayakar, S.M. Dynamic response of a planetary gear system using a finite element/contact mechanics model. J. Mech. Des. 2000, 122, 304-310. [CrossRef]

5. Chen, Y.; Zhu, R.P.; Feng, Z.C.; Jin, G.H.; Zhang, W. Influence of oil film stiffness on natural characteristics of single-rotor three-input helicopter main gearbox. Vibroeng. Proc. 2018, 17, 7-12.

6. Yang, D.; Liu, Y.; Li, S.; Li, X.; Ma, L. Gear fault diagnosis based on support vector machine optimized by artificial bee colony algorithm. Mech. Mach. Theory 2015, 90, 219-229. [CrossRef]

7. Bozca, M. Transmission error model-based optimisation of the geometric design parameters of an automotive transmission gearbox to reduce gear-rattle noise. Appl. Acoust. 2018, 130, 247-259. [CrossRef]

8. Świtoński, E.; Mężyk, A. Selection of optimum dynamic features for mechatronic drive systems. Autom. Constr. 2008, 17, 251-256. [CrossRef]

9. Walha, L.; Fakhfakh, T.; Haddar, M. Nonlinear dynamics of a two-stage gear system with mesh stiffness fluctuation, bearing flexibility and backlash. Mech. Mach. Theory 2009, 44, 1058-1069. [CrossRef]

10. Dzitkowski, T.; Dymarek, A. Active reduction of identified machine drive system vibrations in the form of multi-stage gear units. Mechanics 2014, 20, 183-189. [CrossRef]

11. Dzitkowski, T.; Dymarek, A. Active synthesis of machine drive systems using a comparative method. J. Vibroengineering 2012, $14,528-533$.

12. Dymarek, A.; Dzitkowski, T. Method of active synthesis of discrete fixed mechanical systems. J. Vibroengineering 2012, 14, 458-463.

13. Dymarek, A.; Dzitkowski, T. Inverse task of vibration active reduction of mechanical systems. Math. Probl. Eng. 2016, 2016, 3191807. [CrossRef]

14. Dymarek, A.; Dzitkowski, T.; Herbuś, K.; Ociepka, P.; Sękala, A. Use of active synthesis in vibration reduction using an example of a four-storey building. J. Vib. Control 2020, 26, 1471-1483. [CrossRef]

15. Dymarek, A.; Dzitkowski, T. The use of synthesis methods in position optimisation and selection of tuned mass damper (TMD) parameters for systems with many degrees of freedom. Arch. Control Sci. 2021, 31, 185-211.

16. Redfield, R.C.; Krishnan, S. Dynamic system synthesis with a bond graph approach. Part I: Synthesis of one-port impedances. ASME J. Dyn. Syst. Meas. Control 1993, 115, 357-363. [CrossRef]

17. Park, J.S.; Kim, J.S. Dynamic system synthesis in term of bond graph prototypes. KSME Int. J. 1998, 12, 429-440. [CrossRef]

18. Smith, M.C. Synthesis of mechanical networks: The inerter. IEEE Trans. Autom. Control 2002, 47, 1648-1662. [CrossRef]

19. Kubur, M.; Kahraman, A.; Zini, D.M.; Kienzle, K. Dynamic analysis of a multi-shaft helical gear transmission by finite elements: Model and experiment. J. Vib. Acoust. 2004, 126, 398-406. [CrossRef]

20. Wu, J.S.; Chen, D.W. Torsional vibration analysis of gear-branched systems by finite element method. J. Sound Vib. 2001, 240, 159-182. [CrossRef]

21. Rao, Z.; Zhou, C.Y.; Deng, Z.H.; Fu, M.Y. Nonlinear torsional instabilities in two-stage gear systems with flexible shafts. Int. J. Mech. Sci. 2014, 82, 60-66. [CrossRef]

22. Byrtus, M.; Zeman, V. On modeling and vibration of gear drives influenced by nonlinear couplings. Mech. Mach. Theory 2011, 46, 375-397. [CrossRef]

23. Milanović Smieee, J.V.; Fu, C.P.N.; Radosavljević, R.; Lazarević, Z. Sensitivity of torsional modes and torques to uncertainty in shaft mechanical parameters. Electr. Power Compon. Syst. 2001, 29, 867-881. [CrossRef]

24. Kowal, L.; Sinka, T. Impact of winding drum shell ribbing of a hoisting machine on its strength and manufacture costs. Min. Mach. 2020, 4, 2-13.

25. Adams, M.L. Rotating Machinery Vibration: From Analysis to Troubleshooting, 2nd ed.; CRC Press: Boca Raton, FL, USA, 2010.

26. Rao, J.S. History of Rotating Machinery Dynamics; Springer Science \& Business Media: Bangalore, India, 2011 ; Volume 20.

27. Antoniadou, I.; Manson, G.; Staszewski, W.J.; Barszcz, T.; Worden, K. A time-frequency analysis approach for condition monitoring of a wind turbine gearbox under varying load conditions. Mech. Syst. Signal Process. 2015, 64, 188-216. [CrossRef] 